\title{
Anti-Enteric Neuronal Antibodies and the Irritable Bowel Syndrome
}

\author{
Jackie D Wood, ${ }^{1 *}$ Sumei Liu, ${ }^{2}$ Douglas A Drossman, ${ }^{3}$ Yehuda Ringel ${ }^{3}$ and William E Whitehead ${ }^{3}$ \\ ${ }^{1}$ Department of Physiology and Cell Biology, The Ohio State University Medical Center, Columbus, Ohio, USA; '2Department of Biology, \\ University of Wisconsin-La Crosse, Lacrosse, Wisconsin, USA; and ${ }^{3}$ Department of Medicine, University of North Carolina School of Medicine, \\ Chapel Hill, North Carolina, USA
}

\begin{abstract}
Background/Aims
Functional gastrointestinal disorders are those in which no abnormal metabolic or physical processes, which can account for the symptoms, can be identified. The irritable bowel syndrome (IBS) is a significant functional disorder, which affects 10-20 percent of the population worldwide. Predominant symptoms of IBS are abnormal defecation associated with abdominal pain, both of which may be exacerbated by psychogenic stress. Our study was designed to test a hypothesis that symptoms in a subset of patients with a diagnosis of IBS are associated with an autoimmune degenerative neuropathy in the enteric nervous system.
\end{abstract}

\section{Methods}

Serum was collected from Rome II-IBS patients and controls at the University of North Carolina Functional Gastrointestinal Diseases Center. Assay procedures were immunohistochemical localization of antibody binding to enteric neurons and human protein microarray assay for antigens recognized by antibodies in the sera.

\section{Results}

Eighty-seven percent of IBS sera and 59\% of control sera contained anti-enteric neuronal antibodies. Antibody immunostaining was seen in the nucleus and cytoplasm of neurons in the enteric nervous system. Protein microarray analysis detected antibody reactivity for autoantigens in serum with anti-enteric neuronal antibodies and no reactivity for the same autoantigens in samples not containing anti-enteric neuronal antibodies in our immunostaining assay. Antibodies in sera from IBS patients recognized only 3 antigens out of an 8,000 immunoprotein array. The 3 antigens were: (1) a nondescript ribonucleoprotein (RNP-complex); (2) small nuclear ribonuclear polypeptide A; and (3) Ro-5,200 kDa.

\section{Conclusions}

Results of the present study suggest that symptoms in a subset of IBS patients might be a reflection of enteric neuronal dam age or loss, caused by circulating anti-enteric autoimmune antibodies.

\section{(J Neurogastroenterol Motil 2012;18:78-85)}

Key Words

Autoimmune neuropathy; Enteric nervous system; Gastrointestinal disorders

Received: September 29, 2011 Revised: November 11, 2011 Accepted: November 19, 2011

(c) This is an Open Access article distributed under the terms of the Creative Commons Attribution Non-Commercial License (http://creativecommons. org/licenses/by-nc/3.0) which permits unrestricted non-commercial use, distribution, and reproduction in any medium, provided the original work is properly cited.

*Correspondence: Jackie D Wood, PhD, AGAF

Department of Physiology and Cell Biology, The Ohio State University College of Medicine, Columbus, Ohio 43210, USA

Tel: +1-614-292-5449, Fax: +1-614-292-4888, E-mail: wood.13@osu.edu

Financial support: This study was supported by NIH (2 R01 DK 037238-22, DK031369, R24 DK067674 and M01 RR00046).

Conflicts of interest: None. 


\section{Introduction}

The irritable bowel syndrome (IBS) is a functional gastrointestinal disorder (FGID). IBS diminishes quality of life for $8 \%-20 \%$ of populations worldwide. ${ }^{1-5}$ Predominant symptoms of IBS are abnormal defecation associated with abdominal pain, both of which may be exacerbated by psychogenic stress. ${ }^{1,6}$

A disordered enteric nervous system (ENS) might underlie some forms of IBS pathophysiology. ${ }^{7,8}$ Activity of the musculature, glands and vascular system to generate functionally effective patterns of behavior, which are adaptive for differing digestive states, is controlled by the ENS. The gut does not work without the ENS. This is apparent in its absence in terminal regions of the large intestine in Hirschsprung's disease. ${ }^{9}$ Autoimmune ablation of the ENS in the lower esophageal sphincter underlies the pathophysiology of achalasia. ${ }^{10,11}$ Neuropathic degeneration of ENS neurons in IBS, gastrointestinal (GI) pseudoobstruction, Chagas disease, paraneoplastic syndrome and enteric ganglionitis, underlies the morbidity. ${ }^{12-20}$ Progressive degenerative loss of neurons from the ENS neural networks is reminiscent of dropout of dopaminergic neurons in Parkinson disease where gradual depletion advances from minor symptoms to severe stages of somatic motor dysfunction. Progressive loss and degradation of ENS control of the gut musculature, glands and vasculature is expected to be likewise manifest as steady worsening of gut-related symptoms.

Retrospective review suggests that IBS-like symptoms in a subgroup of patients might be an expression of early stages of a progressive degenerative ENS neuropathy that culminates as intestinal pseudoobstruction when neuronal loss reaches levels that compromise ENS programing of propulsive motility. ${ }^{12,18,20}$ This is reminiscent of chronic GI pseudoobstruction in paraneoplastic syndrome where commonality of antigens between certain cancer cells (eg, small-cell lung carcinoma) and ENS neurons leads to autoimmune attack that destroys the neurons. ${ }^{21}$ Patients with symptoms of pseudoobstruction in combination with small-cell lung carcinoma express IgG autoantibodies that bind to ENS neurons in the stomach and small intestine. ${ }^{21,22}$ This damages, destroys and removes the neurons from the integrative neural networks through induction of apoptosis. ${ }^{14}$

We aimed to evaluate the prevalence of anti-enteric neuronal antibodies in patients diagnosed with idiopathic IBS according to Rome II symptom-based criteria. ${ }^{1,2}$ Our approach was based on one used productively by others for evaluation of anti-enteric neuronal antibodies in patients with the paraneoplastic syndrome. ${ }^{21-23}$ Some of the results have appeared in abstract form. ${ }^{24}$

\section{Materials and Methods}

Blood was drawn from 78 IBS patients and 22 controls in the Center for Functional GI and Motility Disorders at the University of North Carolina, Chapel Hill (UNC). Each patient reported symptoms of abdominal pain a minimum of $25 \%$ of the time in the last 3 months and met Rome II criteria for IBS as confirmed by UNC clinical gastroenterologists. ${ }^{6}$ The controls,
A



B

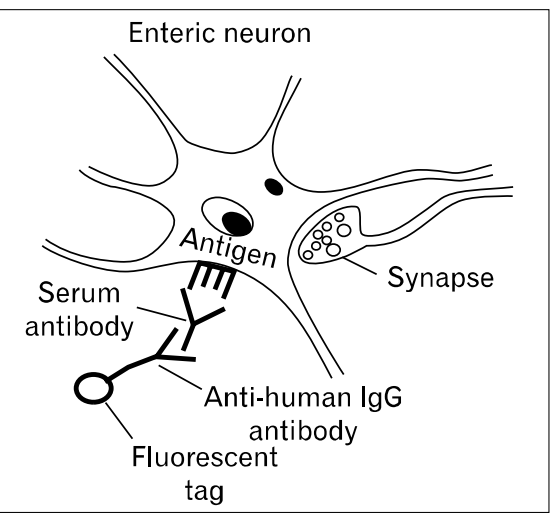

Figure 1. Method used to identify presence of anti-enteric neuronal antibodies in sera. (A) Structure of the anti-enteric neuronal antibodies. Serum was applied to isolated longitudinal muscle with attached myenteric plexus (ie, longitudinal muscle-myenteric plexus preparation) or to isolated submucosal plexus free of the mucosa and muscularis externa (ie, submucosal plexus preparation). (B) Anti-enteric neuronal antibodies (human IgG), if present in the serum, bind to antigenic molecules expressed by anti-enteric neuronal antibodies in neurons. Incubation with a fluorescently-tagged anti-human IgG antibody labels the neurons recognized by antibodies in the serum. 
which were recruited from the UNC gastroenterology unit and by public advertising, reported no significant recurring GI symptoms. The study was approved by the UNC institutional review board and all subjects provided written informed consent.

Sera were separated, coded at UNC and transported frozen to The Ohio State University. Each sample was tested, in blinded manner, for presence of anti-enteric neuronal antibodies. The protocol consisted of incubation of whole-mount preparations of guinea pig ENS with patient or control sera followed by fluorescent immunohistochemistry to visualize antibodies that recognized ENS neurons (Fig. 1).

Whole-mount ENS preparations were obtained from male albino Hartley guinea pigs. The guinea pigs were killed by stunning and exsanguination as approved by The Ohio State University ILAUC (Protocol 2010A0023; approved 2/11/2010; expiration 2/11/2013). The small intestine was removed, immediately flushed with ice-cold Krebs solution and divided into segments that were fixed overnight in Zamboni's fixative. Microdissection was used to prepare whole-mount preparations of the myenteric and submucosal plexuses for immunohistochemistry (Fig. 1A).

Whole-mount preparations were used for indirect immunofluorescence screening for the presence of anti-enteric neuronal antibodies in the samples. The preparations were placed in phosphate buffered saline (PBS) containing 10\% normal donkey serum and $0.3 \%$ Triton $\mathrm{X}-100$ for 30 minutes at room temperature followed by incubation in a serum sample overnight at room temperature. This was followed by washing the tissue in PBS and incubation in indocarbocyanin (Cy3)-labeled donkey anti-human $\operatorname{IgG}(1: 500)$ at room temperature for 1 hour. The tissues were then washed in PBS and cover slipped with Vectashield ${ }^{\circledR}$ mounting medium (Vector lab, Burlingame, CA, USA). Fluorescent labeling was viewed with a Nikon Eclipse 90 i fluorescence microscope (Nikon, Tokyo, Japan) and analyzed with filter combinations that enabled separate visualization of multiple fluorophores. Photomicrographs were acquired with a CoolSnap HQ2 monochrome digital camera (Roper Scientific, Tucson, AZ, USA), stored on disk and analyzed with MetaMorph $\left.{ }^{(}\right)$software (MetaMorph, Carl Zeiss Meditec, Göttingen, Germany). Specificity of labeling of ENS neurons by antibodies in the serum samples was verified by pre-absorbing antibodies in the sample with a liver substrate $(100 \mathrm{mg} / \mathrm{mL}$; Sigma-Aldrich, St. Louis, MO, USA) and finding no differences in immunostaining for serum exposed or not exposed to liver substrate. ${ }^{22}$ Whole sections of liver or kidney were exposed to serum samples that produced in- tense neuronal staining and examined for fluorescent staining as an added control for specificity.

Serum samples were screened initially at a dilution of 1:50. When immunoreactivity was found, stepwise doubling of dilutions was done until no staining above background was evident. The final dilution that yielded staining above background was recorded as the antibody titer. Samples were scored blindly by 3 experienced ENS histologists with a semiquantitative rating scale where: " 0 " = no neuronal fluorescent staining above background; "1" = moderate intensity of fluorescent staining; and "2" = intense fluorescent staining. Background staining was defined as that produced when the secondary anti-human IgG antibody alone was applied.

Two-way contingency tables were generated with frequency, percentage, row percentage and column percentage. Fisher's exact test was used to test associations between 2 category variables. A $P$-value $<0.05$ represented statistical significance in hypothesis testing.

The serum samples were analyzed with Invitrogen ProtoArray ${ }^{\mathrm{R}}$ human protein microarray immune response biomarker profiling kit (Cat. PAH0525102; Invitrogen, Carlsbad, CA, USA). Serum samples, which were determined to contain anti-enteric neuronal antibodies by immunostaining assay, were coded and compared blindly with a coded set that did not contain antibody immunoreactivity in the assay. We used Invitrogen's ProtoArray ${ }^{\circledR}$ human protein microarray $\mathrm{v} 4.1$ immune response biomarker profiling kit (Invitrogen), which screens for 8,000 unique proteins associated with the human immunoglobulin lambda locus. This locus is a region on chromosome 22 that contains genes for lambda antibody light chains.

ProtoArray data were analyzed with ProtoArray ${ }^{\circledR}$ Prospector v5.0 (Invitrogen). This is a freeware software program from Invitrogen $^{\mathrm{TM}}$ designed for identification of antibodies on the ProtoArray ${ }^{(\mathbb{R}}$ microarray that are bound by extrinsic antibodies applied as a mixture of antibodies in a serum sample. ProtoArray ${ }^{\circledR}$ Prospector analyzes results where any bound antibody in the sample is detected by probing with a second fluorescently-labeled, IgG class-specific antibody. Binding of the second antibody on the microarray is then quantified by measuring the fluorescence intensity of each spot on the microarray profile. Values (Z-factors) for the fluorescent signals are calculated by taking into account corrections for background and negative controls on the microarray. The program identifies signals that have $\mathrm{Z}$-factors greater than a user-defined cut-off; the cut-off was set at 0.4. Z-factors $>0.4$ were scored as positive "hits". The program nor- 
malizes values for fluorescence intensity and calculates $\mathrm{Z}$-scores by subtracting the mean value of the entire population distribution and dividing by the standard deviation. Z-scores above a threshold of 3 were considered positive "hits".

\section{Results}

Figure 2 illustrates results obtained with our immunofluorescent assay for presence of autoimmune anti-enteric neuronal antibodies in IBS sera. Presence of anti-enteric neuronal antibodies was revealed as fluorescent staining of neuronal cell bodies following incubation with patients' serum. The fluorescence was emitted from anti-human IgG antibodies, which were bound to anti-enteric neuronal antibodies in the serum, which in turn, were bound to antigens expressed by the neurons (Fig. 1). When anti-enteric neuronal antibodies were present, double labeling with an antibody against the pan-neuronal marker $\mathrm{HuC} / \mathrm{D}$ showed neurons to be the only cell type recognized by the antibodies (Fig. $2 \mathrm{~A}$ and $2 \mathrm{~B}){ }^{25}$ Sera from 78 IBS patients and 22 controls were examined. The patients were categorized as diarrhea predom-
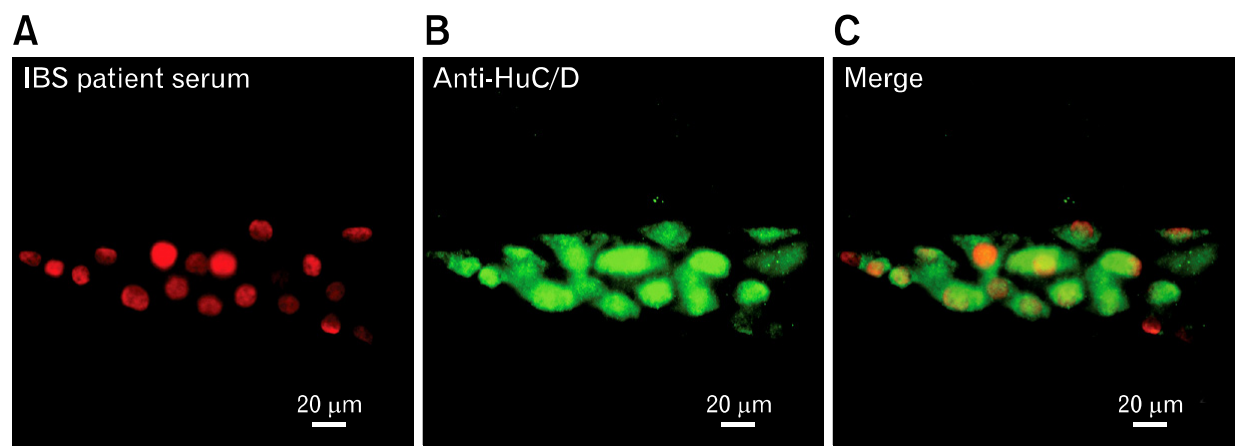

Figure 2. Anti-enteric neuronal antibodies in serum from irritable bowel syndrome patient GCRC 2115. (A) Ganglion in the myenteric plexus stained with fluorescently-labeled anti-human IgG following incubation with patient's serum. Antibodies in the serum reacted with virtually all ganglion cells. Reaction is restricted to ganglion cell nuclei for this case. (B) The same ganglion stained with anti-human neuronal protein $\mathrm{HuC} / \mathrm{HuD}$, which identifies all neuronal cell bodies in the ganglion. Anti-HuC/HuD immunoreactivity was expressed in the nucleus and cytoplasm and therefore outlined the entire cell body. (C) Digital merger of patient's antibody staining and anti-Hu. IBS, irritable bowel syndrome.

Table 1. Results for Irritable Bowel Syndrome Patients and Controls With or Without Anti-Enteric Neuronal Antibodies

\begin{tabular}{|c|c|c|c|c|}
\hline & \multicolumn{3}{|c|}{ Patients $(\mathrm{n}=76)$} & \multirow{2}{*}{ Controls $(\mathrm{n}=22)$} \\
\hline & IBS-C & IBS-D & IBS-A/M & \\
\hline \multicolumn{5}{|l|}{$\operatorname{Sex}(n[\%])$} \\
\hline Female & $6(7.9)$ & $15(19.7)$ & $34(44.7)$ & $22(100)$ \\
\hline Male & $1(1.3)$ & $6(7.9)$ & $14(18.4)$ & - \\
\hline \multicolumn{5}{|c|}{ Age (mean $\pm \mathrm{SD}, \mathrm{yr})$} \\
\hline Female & $36.5 \pm 12.0$ & $30.9 \pm 10.0$ & $32.4 \pm 12.6$ & $39.6 \pm 14.8$ \\
\hline Male & $32.0 \pm 00.0$ & $38.5 \pm 6.2$ & $31.6 \pm 10.0$ & - \\
\hline \multicolumn{5}{|l|}{ Stain (n) } \\
\hline \multicolumn{5}{|l|}{ Female } \\
\hline 0 & 2 & 2 & 4 & 9 \\
\hline 1 & 4 & 10 & 23 & 9 \\
\hline 2 & 0 & 3 & 7 & 4 \\
\hline \multicolumn{5}{|l|}{ Male } \\
\hline 0 & 0 & 1 & 3 & - \\
\hline 1 & 0 & 4 & 8 & - \\
\hline 2 & 1 & 1 & 3 & - \\
\hline
\end{tabular}

Immunostain intensity was scored as $0=$ no staining, $1=$ moderate staining and $2=$ intense staining for myenteric neurons. Mean stain intensity derived from scores entered by 3 observers.

IBS-C, constipation predominant IBS; IBS-D, diarrhea predominant IBS; IBS-A/M, alternating/mixed IBS. 
inant, constipation predominant or alternating/mixed according to Rome II criteria for IBS diagnosis. ${ }^{1,6}$ Results for 76 patients (sera from 2 patients were compromised in handling) and the controls appear in Table 1.

Sera from 66 (86.8\%) of the 76 tested IBS patients had antibodies that bound and labeled ENS neurons (Table 1). Sera from the remaining 12 IBS patients did not have demonstrable anti-enteric neuronal antibodies. Sera from 13 (59.1\%) of 22 controls contained the antibodies (Table 1). Antibody staining intensities of " 1 " and " 2 " were treated as antibody presence and "0"-staining was treated as absence of antibodies in construction of a two-way contingency table. Fisher's exact test was used to test for independence of association between the patient and control groups. The proportion of the patient group that had anti-enteric antibodies in the serum (ie, 66 of 76) was significantly different from the control group (ie, 13/22) with a $P$-value of 0.005 . Antibody titers were variable in a wide range from 1:400 to $1: 409,600$ for IBS patients (mean $\pm \mathrm{SD}=1: 19,887 \pm 67,932$; $\mathrm{n}=66$ ) and $1: 400$ to $1: 409,600$ for controls (mean $\pm \mathrm{SD}=$ $1: 118,500 \pm 195,267 ; \mathrm{n}=13)$. The differences were significant $(P<0.05$; unpaired $t$ test $)$.

Antibody staining, when present in patient and control sera, occurred in the neuronal nuclei alone, in the cytoplasm alone or in both nucleus and cytoplasm (Fig. 3). Immunostaining in the neuronal nuclei predominated ( $78.5 \%$ of 79 samples) relative to staining of the cytoplasm alone ( $10.1 \%$ of the samples) or staining of both nuclei and cytoplasm (11.3\%) for patients and controls (Fig. 3). There were no significant differences between males and females in terms of nuclear vs cytoplasmic vs nuclear and cytoplasmic staining.

The predominance of nuclear staining was consistent with the protein microarray data in Table 2 . Analysis, with sensitivity for 8,000 human proteins associated with the immunoglobulin lambda locus, detected antibody reactivity for only three autoantigens in serum samples containing anti-enteric neuronal antibodies, as determined by immunostain assay. No antibody re-
A

Nucleus

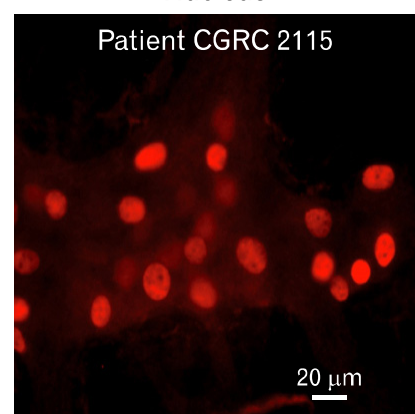

B

\begin{tabular}{lcc}
\hline Location & IBS patients $(\mathrm{n}[\%])$ & Controls $(\mathrm{n}[\%])$ \\
\hline Nucleus & $53(80.3)$ & $9(69.2)$ \\
Cytoplasm & $5(7.6)$ & $3(23.1)$ \\
Nucleus and cytoplasm & $8(12.1)$ & $1(7.7)$ \\
\hline
\end{tabular}

Nucleus and cytoplasm
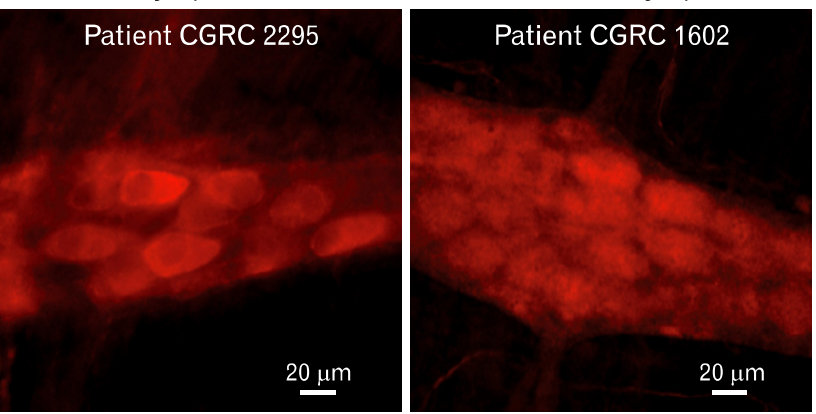

Figure 3. Immunostaining pattern for sera collected from 76 irritable bowel syndrome patients, 66 of whom had anti-enteric neuronal antibodies in their blood, and 22 controls, 13 of whom had anti-enteric neuronal antibodies in their blood. (A) Examples of immunostaining in the nucleus alone, the cytoplasm alone and in both nucleus and cytoplasm. (B) Immunostaining in the neuronal nuclei predominated relative to staining of the cytoplasm alone or staining of nuclei and cytoplasm. IBS, irritable bowel syndrome.

Table 2. Results Obtained With Invitrogen, Inc. Immune Response Biomarker Profiling Assay

\begin{tabular}{|c|c|c|c|c|c|c|c|c|}
\hline Protein name & $\begin{array}{l}\text { IBS-A signal } \\
\text { (density) }\end{array}$ & $\begin{array}{l}\text { IBS-B signal } \\
\text { (density) }\end{array}$ & $\begin{array}{l}\text { IBS-A } \\
\text { Z-score }\end{array}$ & $\begin{array}{l}\text { IBS-B } \\
\text { Z-score }\end{array}$ & $\begin{array}{c}\text { IBS-A } \\
\text { Z-factor }\end{array}$ & $\begin{array}{l}\text { IBS-B } \\
\text { Z-factor }\end{array}$ & $\begin{array}{l}\text { IBS-A } \\
\text { (hit) }\end{array}$ & $\begin{array}{c}\text { IBS-B } \\
\text { (hit) }\end{array}$ \\
\hline Ribonucleoprotein complex & $56,544.5$ & 184 & 51.727 & 0.072 & 0.895 & -6.286 & 1 & 1 \\
\hline Small nuclear ribonuclear polypeptide A & 7,530 & 49 & 6.783 & 0.404 & 0.807 & -7.820 & 1 & 0 \\
\hline Anti-Ro 5,200 MW & $254,043.5$ & 338.5 & 22.843 & 0.239 & 0.775 & -6.494 & 1 & 0 \\
\hline
\end{tabular}

IBS, irritable bowel syndrome; IBS-A, serum samples with anti-enteric nueronal antibodies; IBS-B, serum samples without anti-enteric neuronal antibodies.

Three blinded samples known to contain anti-enteric neuronal antibodies in immunostain assays (IBS-A) and 3 samples without antibodies in immunostain assays (IBS-B) were pooled. Out of 8,000 possibilities, 3 antigens were identified as reacting with antibodies in the IBS-A sera. No "hits" were obtained with IBS-B sera. The 3 identified antigens ("hits") in IBS-A sera consisted of a nondescript ribonucleoprotein complex, Anti-Ro 52,000 MW and small nuclear ribonucleoprotein polypeptide A. 
activity for the same autoantigens was found in serum samples that did not contain the antibodies in our immunostain assay. Antibody titers for a nondescript macromolecular complex containing both protein and RNA molecules (ie, ribonucleoprotein complex) and small ribonuclear polypeptide A were present in high titers in the same sera that contained anti-enteric neuronal antibodies in our neuronal assays. Moderate levels of anti-Ro 52,000 MW antibody were present also in antibody-containing IBS sera and not in sera devoid of antibodies in immunostain assays (Table 2).

\section{Discussion}

Three outcomes are noteworthy in terms of the etiopathogenesis of IBS and FGIDs: (1) Anti-enteric neuronal antibodies, present in sera from IBS patients, suggest that an autoimmune degenerative neuropathy in the ENS might underlie their symptoms, (2) The high proportion of IBS patients with the antibodies in their blood (84.2\%) is unexpectedly high and suggests that autoimmune damage and loss of neurons in the ENS might be an important factor underlying their symptoms and (3) The anti-enteric neuronal antibodies in IBS are directed only to three previously unrecognized kinds of antigens expressed by ENS neurons and no other cell type in the intestine.

Anti-enteric neuronal antibodies in the IBS patients in our study are reminiscent of paraneoplastic neurological disease. ${ }^{26}$ Disordered gut motility associated with the paraneoplastic syndrome is explained as due to commonality of antigens between some cancers (eg, small-cell lung carcinoma) and ENS neurons. Antibody recognition of the antigens underlies the autoimmune attack, which results in decimation of neurons that form the ENS integrative circuitry. ${ }^{27,28}$ The antibodies, after binding, induce apoptosis in guinea pig ENS neurons. Apoptosis in ENS neurons involves mitochondrial events as indicated by specific activation of effector caspase- 3 and the cytochrome C-dependent proapoptotic messenger apaf-1. ${ }^{14}$ The neuronal autoantibody commonly associated with paraneoplastic dysmotility in the gut is the Type-1 anti-neuronal nuclear antibody. ${ }^{29,30}$ This antibody binds to the nuclear protein $\mathrm{Hu}$, which is part of a family of conserved RNA-binding proteins that includes $\mathrm{HuC}, \mathrm{HuD}$ and $\mathrm{HuR}$. These proteins are expressed in neurons of the ENS as well as other autonomic ganglia, sensory neurons and the central nervous system (Fig. 2B).

\section{Irritable Bowel Syndrome Autoantibodies}

Antibodies in IBS sera in the present study were restricted to recognition of only 3 antigens out of 8,000 in an immunoprotein array. The 3 antigens were: (1) a nondescript ribonucleoprotein (RNP-complex), (2) small nuclear ribonuclear polypeptide A and (3) Ro-5,200 kDa.

The IBS-related antigens are RNA-binding proteins like those of the $\mathrm{Hu}$ family, but otherwise different. This suggests that presence of autoantibodies, which recognize the 3 kinds of antigens, might prove to be a useful diagnostic marker for IBS and perhaps other FGIDs where disordered ENS function is suspect. RNP-complexes are involved in RNA processing and transport. TAR DNA-binding protein (TDP-43), the survival motor neuron protein and fragile-X mental retardation protein are three ubiquitous proteins of this nature mainly associated with defects in localized parts of the central nervous system. ${ }^{31}$ Significance of the RNP-complex in ENS neurons and susceptibility to disruption by autoantibodies is unexplored. The second antigen, small nuclear ribonuclear polypeptide $A$, also known as $U-1 A$, is a $70 \mathrm{kDa}$ peptide recognized by anti-ribonuclear protein autoantibodies associated with mixed connective tissue diseases (ie, arthralgias, Raynaud's phenomenon, arthritis, myositis, pulmonary fibrosis and sclerodactyly. ${ }^{32,33}$ Autoantibodies to the third antigen, Ro-5,200, were first reported in the serum of patients with Sjögrens syndrome. ${ }^{34}$ Aside from Sjögrens syndrome, anti-Ro $5,200 \mathrm{kDa}$ reactivity is found in systemic lupus erythematosus, scleroderma, dermatomyositis and systemic sclerosis. $^{35,36}$

Our findings suggest that presence of antibodies to the three ribonuclear proteins might not be unique to IBS and that IBS can be added to the spectrum of disorders associated with autoantibody binding to ribonucleoproteins. The proportion of control sera with anti-enteric neuronal antibodies in our study is noticeably large and might be a reflection of the scope of the disorders associated with the autoimmune-ribonucleoprotein interface in tertiary medical care populations. Overall, we cannot exclude the possibility that some of the Rome II IBS patients and/or controls, with circulating antibodies to one or the other of the three ribonucleoprotein antigens in our study, did not have an autoimmune disease.

\section{Acknowledgements}

We are indebted to Susan D Desmond-Hellmann, Joseph S 
McCracken, Ward Ortmann, Timothy Behrens and Ricardo Ferreira at Genentech, Inc., South San Francisco, CA for their assistance with ProtoMicroarray analysis.

Author contributions: JDW, concept-design implementation, study supervision, analysis and interpretation of data, statistical analysis drafting of the manuscript; SL, acquisition of immunohistochemical data, analysis and interpretation, manuscript editing; DAG, selection and evaluation of patients, interpretation of results; YR, patient selection and evaluation, interpretation of results; WEW, study supervision, selection and evaluation of patients and controls, acquisition of study material, statistical analysis and interpretation of data, drafting of the manuscript.

\section{References}

1. Drossman DA. The functional gastrointestinal disorders and the Rome III process. Gastroenterology 2006;130:1377-1390.

2. Ringel Y, Sperber AD, Drossman DA. Irritable bowel syndrome. Annu Rev Med 2001;52:319-338.

3. Gwee KA, Wee S, Wong ML, Png DJ. The prevalence, symptom characteristics, and impact of irritable bowel syndrome in an Asian urban community. Am J Gastroenterol 2004;99:924-931.

4. Pan G, Lu S, Ke M, Han S, Guo H, Fang X. Epidemiologic study of the irritable bowel syndrome in Beijing: stratified randomized study by cluster sampling. Chin Med J (Engl) 2000;113:35-39.

5. Quigley EM. Changing face of irritable bowel syndrome. World J Gastroenterol 2006;12:1-5.

6. Thompson WG, Longstreth GL, Drossman DA, Heaton K, Irvine EJ, Muller-lissner S. Functional bowel disorders and functional abdominal pain. In: Drossman DA, Corazziari E, Talley NJ, Ghromspn WG, Whitehead WE, eds. Rome II: The functional gastrointestinal disorders. 2nd ed. McLean: Degnon Associates 2000: 351-432.

7. Wood JD. Pathophysiology underlying the irritable bowel syndrome. In: Johnson LR, Barrett KE, Ghishan FK, Merchant JL, Said HM, Wood JD, eds. Physiology of the gastrointestinal tract. 4th ed. San Diego: Academic Press 2006:1009-1031.

8. Wood JD. Neuropathophysiology of functional gastrointestinal disorders. World J Gastroenterol 2007;13:1313-1332.

9. Knowles $\mathrm{CH}$. New horizons in the pathogenesis of gastrointestinal neuromuscular disease. J Pediatr Gastroenterol Nutr 2007;45(suppl 2):S97-S102.

10. Verne GN, Sallustio JE, Eaker EY. Anti-myenteric neuronal antibodies in patients with achalasia. A prospective study. Dig Dis Sci 1997;42:307-313.

11. Moses PL, Ellis LM, Anees MR, et al. Antineuronal antibodies in idiopathic achalasia and gastro-oesophageal reflux disease. Gut 2003;52:629-636.

12. Krishnamurthy S, Heng Y, Schuffler MD. Chronic intestinal pseudo-obstruction in infants and children caused by diverse abnormalities of the myenteric plexus. Gastroenterology 1993;104:1398-1408.

13. De Giorgio R, Barbara G, Stanghellini V, et al. Clinical and morphofunctional features of idiopathic myenteric ganglionitis underlying severe intestinal motor dysfunction: a study of three cases. Am J Gastroenterol 2002;97:2454-2459.

14. De Giorgio R, Bovara M, Barbara G, et al. Anti-HuD-induced neuronal apoptosis underlying paraneoplastic gut dysmotility. Gastroenterology 2003;125:70-79.

15. De Giorgio R, Guerrini S, Barbara G, Cremon C, Stanghellini V, Corinaldesi R. New insights into human enteric neuropathies. Neurogastroenterol Motil 2004;16(suppl 1):143-147.

16. De Giorgio R, Guerrini S, Barbara G, et al. Inflammatory neuropathies of the enteric nervous system. Gastroenterology 2004;126: 1872-1883.

17. De Giorgio R, Stanghellini V, Barbara G, et al. Primary enteric neuropathies underlying gastrointestinal motor dysfunction. Scand J Gastroenterol 2000;35:114-122.

18. Wood JD. Neuropathy in the brain-in-the-gut. Eur J Gastroenterol Hepatol 2000;12:597-600.

19. Törnblom H, Lindberg G, Nyberg B, Veress B. Full-thickness biopsy of the jejunum reveals inflammation and enteric neuropathy in irritable bowel syndrome. Gastroenterology 2002;123:1972-1979.

20. Linberg G, Törnblom H, Iwarzon M, Nyberg B, Martin JE, Veress B. Full-thickness biopsy findings in chronic intestinal pseudo-obstruction and enteric dysmotility. Gut 2009;58:1084-1090.

21. Lennon VA, Sas DF, Busk MF, et al. Enteric neuronal autoantibodies in pseudoobstruction with small-cell lung carcinoma. Gastroenterology 1991;100:137-142.

22. Galanis E, Frytak S, Rowland KM Jr, Sloan JA, Lennon VA. Neuronal autoantibody titers in the course of small-cell lung carcinoma and platinum-associated neuropathy. Cancer Immunol Immunother 1999;48:85-90.

23. Nguyen-tat M, Pohl J, Günter E, et al. Severe paraneoplastic gastroparesis associated with anti-Hu antibodies preceding the manifestation of small-cell lung cancer. Z Gastroenterol 2008;46:274-278.

24. Wood JD, Liu S, Ren W, Whitehead WE. Autoimmune degenerative neuropathy in the enteric nervous system (ENS) in functional gastrointestinal disorders (FGIDs). Gastroenterology 2010;138 (suppl 1):S586-S587.

25. Lin Z, Gao N, Hu HZ, et al. Immunoreactivity of Hu proteins facilitates identification of myenteric neurons in guinea-pig small intestine. Neurogastroenterol Motil 2002;14:197-204.

26. King PH, Redden D, Palmgren JS, Nabors LB, Lennon VA. Hu antigen specificities of ANNA-I autoantibodies in paraneoplastic neurological disease. J Autoimmun 1999;13:435-443.

27. Schuffler MD, Baird HW, Fleming CR, et al. Intestinal pseudo-obstruction as the presenting manifestation of small-cell carcinoma of the lung. A paraneoplastic neuropathy of the gastrointestinal tract. Ann Intern Med 1983;98:129-134.

28. Kashyap P, Farrugia G. Enteric autoantibodies and gut motility disorders. Gastroenterol Clin North Am 2008;37:397-410.

29. Dropcho EJ. Remote neurologic manifestations of cancer. Neurol Clin 2002;20:85-122, vi.

30. Lennon VA. Calcium channel and related paraneoplastic disease autoantibodies. In: Peter JB, Shoenfeld Y, eds. Autoantibodies. Amsterdam: Elsevier 1996:139-146.

31. Ule J. Ribonucleoprotein complexes in neurologic diseases. Curr Opin Neurobiol 2008; 18:516-523.

32. Lundberg I, Nyman U, Pettersson I, Hedfors E. Clinical manifes- 
tations and anti-(U1)snRNP antibodies: a prospective study of 29 anti-RNP antibody positive patients. Br J Rheumatol 1992;31:811817.

33. Nyman U, Lundberg I, Hedfors E, Pettersson I. Recombinant $70-\mathrm{kD}$ protein used for determination of autoantigenic epitopes recognized by anti-RNP sera. Clin Exp Immunol 1990;81:52-58.

34. Ben-Chetrit E, Chan EKL, Sullivan KF, Tan EM. A 52-kD protein is a novel component of the SS-A/Ro antigenic particle. J Exp Med
1988;167:1560-1571.

35. Peene I, Meheus L, Veys EM, De Keyser F. Detection and identification of antinuclear antibodies (ANA) in a large and consecutive cohort of sera referred for ANA testing. Ann Rheum Dis 2001;60: 1131-1136.

36. Parker JC, Burlingame RW, Bunn CC. Prevalence of antibodies to Ro- 52 in a serologically defined population of patients with systemic sclerosis. J Autoimmune Dis 2009;6:2-7. 